\title{
Technical Note: Intercomparison of formaldehyde measurements at the atmosphere simulation chamber SAPHIR
}

\author{
A. Wisthaler ${ }^{1}$, E. C. Apel ${ }^{2}$, J. Bossmeyer ${ }^{3, *}$, A. Hansel ${ }^{1}$, W. Junkermann ${ }^{4}$, R. Koppmann ${ }^{3, * *}$, R. Meier ${ }^{4}$, K. Müller ${ }^{5}$, \\ S. J. Solomon ${ }^{6}$, R. Steinbrecher ${ }^{4}$, R. Tillmann ${ }^{3}$, and T. Brauers ${ }^{3}$ \\ ${ }^{1}$ Institut für Ionenphysik und Angewandte Physik, Leopold-Franzens-Universität Innsbruck (IAP-LFUI), Innsbruck, Austria \\ ${ }^{2}$ Atmospheric Chemistry Division, National Center for Atmospheric Research (NCAR), Boulder, USA \\ ${ }^{3}$ Institut für Chemie und Dynamik der Geosphäre, ICG-II: Troposphäre, Forschungszentrum Jülich, Germany \\ ${ }^{4}$ Institut für Meteorologie u. Klimaforschung, Atmosph. Umweltforschung (IMK-IFU), Garmisch-Partenkirchen, Germany \\ ${ }^{5}$ Leibniz-Institut für Troposphärenforschung (ift), Leipzig, Germany \\ ${ }^{6}$ Institut für Umweltphysik, Universität Bremen (iup-UB), Bremen, Germany \\ *now at: Cohausz \& Florack, patent attorneys, Düsseldorf, Germany \\ *** now at: Fachbereich C, Atmosphärenphysik, Bergische Universität Wuppertal, Wuppertal, Germany
}

Received: 20 September 2007 - Published in Atmos. Chem. Phys. Discuss.: 6 November 2007

Revised: 27 February 2008 - Accepted: 12 March 2008 - Published: 17 April 2008

\begin{abstract}
The atmosphere simulation chamber SAPHIR at the Research Centre Jülich was used to test the suitability of state-of-the-art analytical instruments for the measurement of gas-phase formaldehyde (HCHO) in air. Five analyzers based on four different sensing principles were deployed: a differential optical absorption spectrometer (DOAS), cartridges for 2,4-dinitrophenylhydrazine (DNPH) derivatization followed by off-line high pressure liquid chromatography (HPLC) analysis, two different types of commercially available wet chemical sensors based on Hantzsch fluorimetry, and a proton-transfer-reaction mass spectrometer (PTRMS). A new optimized mode of operation was used for the PTR-MS instrument which significantly enhanced its performance for online HCHO detection at low absolute humidities.

The instruments were challenged with typical ambient levels of HCHO ranging from zero to several ppb. Synthetic air of high purity and particulate-filtered ambient air were used as sample matrices in the atmosphere simulation chamber onto which $\mathrm{HCHO}$ was spiked under varying levels of humidity and ozone. Measurements were compared to mixing ratios calculated from the chamber volume and the known amount of HCHO injected into the chamber; measurements were also compared between the different instruments. The formal and blind intercomparison exercise was conducted
\end{abstract}

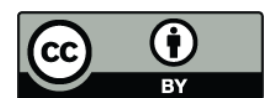

Correspondence to: T. Brauers (th.brauers@fz-juelich.de) under the control of an independent referee. A number of analytical problems associated with the experimental set-up and with individual instruments were identified, the overall agreement between the methods was fair.

\section{Introduction}

Formaldehyde (HCHO) is an important indoor and outdoor air pollutant. It adversely affects human health (e.g. Rumchev et al., 2002; Solomon et al., 2008) and plays a key role as an intermediate in the tropospheric photochemical oxidation of hydrocarbons. It impacts hydroxyl $(\mathrm{OH})$ and hydro-peroxy $\left(\mathrm{HO}_{\mathrm{x}}\right)$ photochemistry and ozone $\left(\mathrm{O}_{3}\right)$ formation (e.g. Sumner et al., 2002; Liu et al., 2007). HCHO is ubiquitously found throughout the troposphere with levels ranging from a few ppt in clean background air conditions to a few tens of ppb in polluted atmospheres such as metropolitan areas or contaminated indoor environments (e.g. Dingle and Franklin, 2002; Koppmann and Wildt, 2007).

A number of techniques have been developed for atmospheric HCHO measurements including: (i) in-situ spectroscopic methods such as Fourier transform infrared spectroscopy (FTIR), differential optical absorption spectroscopy (DOAS) and tunable diode laser absorption spectroscopy (TDLAS), (ii) derivatization-chromatography methods such as 2,4-dinitrophenylhydrazine (DNPH) derivatization followed by gas chromatography (GC) or high pressure liquid

Published by Copernicus Publications on behalf of the European Geosciences Union. 


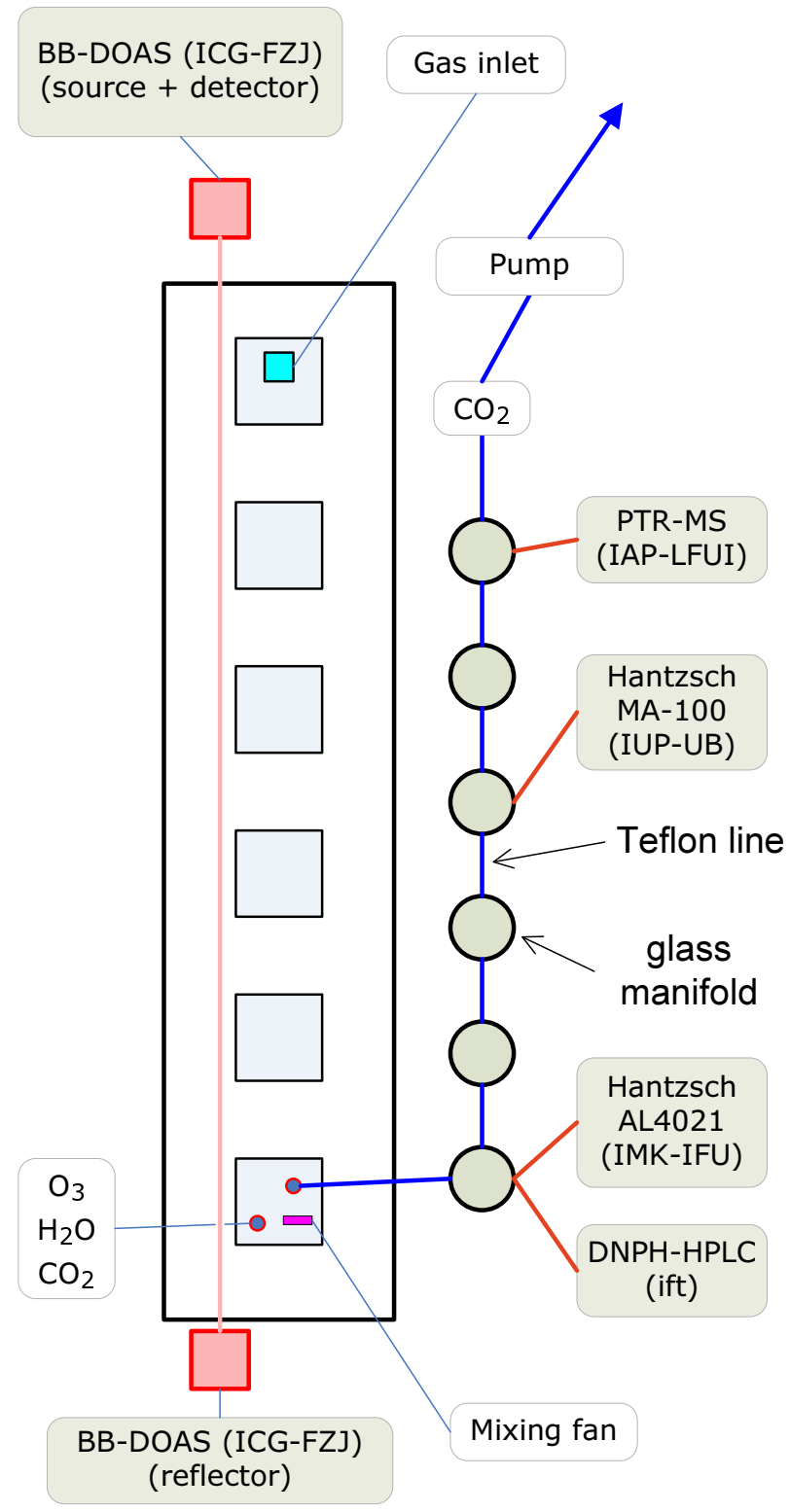

Fig. 1. Setup of the instruments at SAPHIR (top view onto the chamber floor). The squares indicate the instrument flange plates in the chamber floor. The red vertical line indicates the broad-band DOAS absorption light path. The blue line indicates the Teflon line connecting the glass manifolds. The HCHO instruments were connected to these manifolds using their individual inlet lines. The $\mathrm{CO}_{2}$ sensors in the chamber and at the end of the Teflon line were used to detect possible leaks in the line since the chamber air is virtually $\mathrm{CO}_{2}$-free. chromatography (HPLC), (iii) fluorimetric techniques based on the Hantzsch reaction or the formaldehyde dehydrogenase catalyzed reduction of $\mathrm{NAD}^{+}$to $\mathrm{NADH}$, (iv) online chemical ionization methods such as proton-transfer-reaction mass spectrometry (PTR-MS), and (v) remote spectroscopic methods used on satellite-borne platforms (Heard, 2006, and references therein).

For method validation purposes, a number of intercomparison exercises have been performed in the last two decades which have been thoroughly reviewed in a recent paper by Hak et al. (2005). The authors summarize that the level of agreement during these past intercomparisons varied from good to quite poor, with no obvious patterns discernible. Their own intercomparison exercise revealed significant discrepancies and confirmed the need for more method validation work.

In this study we challenged five state-of-the-art $\mathrm{HCHO}$ sensors (DOAS, DNPH-HPLC, Hantzsch (2), and PTRMS) in an intercomparison exercise conducted at the atmosphere simulation chamber SAPHIR at the Research Centre Jülich (FZJ). We performed five days of formal blind inter-comparison experiments with an independent referee (E. Apel, NCAR). The experiments took place under near natural conditions varying the $\mathrm{H}_{2} \mathrm{O}$ and $\mathrm{O}_{3}$ concentrations in the chamber. This study was part of the Quality Assurance Integration Task within ACCENT (Atmospheric Composition Change - The European Network of Excellence). It was also part of a larger OVOC measurement intercomparison campaign. Simultaneously with $\mathrm{HCHO}$, a series of other compounds were injected into the chamber to generate ppb levels of aldehydes and ketones (acetaldehyde, butanal, hexanal, benzaldehyde, methacrolein, acetone, methyl vinyl ketone), pure hydrocarbons (n-butane, toluene), esters (methyl acetate) and alcohols (methanol, ethanol, 1propanol, 1-butanol, 2-methyl-3-buten-2-ol). Results from the other species, obtained by using additional instruments, will be presented in a separate publication (E. Apel et al. ${ }^{1}$ ).

\section{Description of the formaldehyde instruments}

Table 1 overviews the instruments participating in the $\mathrm{HCHO}$ intercomparison exercise. The inlet-based instruments $(1,2$, 3, and 5; Hantzsch, DNPH, and PTR-MS) were connected to manifolds which were continuously flushed with chamber air (see Sect. 3.2 and Fig. 1). The variety of deployed techniques allowed us to compare results from a true in-situ technique such as DOAS (which measured $\mathrm{HCHO}$ mixing ratios in the chamber) with results from inlet-based instruments. Since spatial gradients were eliminated in the well-mixed atmosphere simulation chamber, spatial DOAS measurements

\footnotetext{
${ }^{1}$ E.C. Apel, T. Brauers, R. Koppmann, et al.: Intercomparison of oxygenated volatile organic compound (OVOC) measurements at the SAPHIR atmosphere simulation chamber, submitted to J. Geophys. Res., 2008.
} 
Table 1. Overview of instrumental parameters of the HCHO instruments, details are described in the instruments section.

\begin{tabular}{lllccccc}
\hline & & & \multicolumn{4}{c}{ instrument details } \\
\cline { 4 - 6 } \# & Instrument & Group & accuracy & $\begin{array}{c}\text { precision } \\
(1-\sigma)^{\mathrm{a}}\end{array}$ & $\begin{array}{c}\text { detection } \\
\text { limit }(2-\sigma)\end{array}$ & $\begin{array}{c}\text { time } \\
\text { resolution }\end{array}$ & calibration \\
\hline 1 & Hantzsch AL4021 & IMK-IFU & $5 \%$ & $5 \%$ & $50 \mathrm{ppt}$ & $60 \mathrm{~s}$ & single-point liquid standard \\
2 & Hantzsch MA-100 & iup-UB & $8 \%$ & $1 \%$ & $80 \mathrm{ppt}$ & $120 \mathrm{~s}$ & HCHO permeation tube \\
3 & DNPH-HPLC & ift & $15 \%$ & $10 \%$ & $40 \mathrm{ppt}$ & $1-2 \mathrm{~h}$ & 3-point liquid standard \\
4 & BB-DOAS & ICG-FZJ & $6 \%$ & $20 \%$ & $400 \mathrm{ppt}$ & $100 \mathrm{~s}$ & literature absorption cross section \\
5 & PTR-MS & IAP-LFUI & $10 \%$ & $10 \%$ & $200 \mathrm{ppt}$ & $2 \mathrm{~s}$ b & ion-molecule reaction kinetics \\
\hline
\end{tabular}

a: Precision determined at $1 \mathrm{ppb} \mathrm{HCHO}$ mixing ratio.

b: $2 \mathrm{~s}$ measurement for HCHO, repeated every $75 \mathrm{~s}$.

could be directly compared with point measurements from the inlet-based instruments. Finally, we were able to crossvalidate a variety of calibration methods (gas-phase standards, liquid standards, absolute measurements).

\subsection{Hantzsch AL4021 (IMK-IFU)}

A commercially available instrument (AL4021, Aerolaser $\mathrm{GmbH}$, Garmisch-Partenkirchen, Germany) was used for HCHO detection (Junkermann and Burger, 2006). The technique for the measurement of gas-phase $\mathrm{HCHO}$ using the fluorimetric Hantzsch reaction in the liquid phase requires the quantitative transfer of $\mathrm{HCHO}$ from the gas phase into the liquid phase. The stripping of the water soluble HCHO from the air was carried out using a temperature controlled stainless steel stripping coil with well known surface area and gas and liquid flows. Stainless steel was used as it is simpler to maintain at a stable temperature. Gas and liquid flows were separated behind the coil and the liquid was further analyzed. The technique was calibrated using liquid standards by calculating the gas phase concentration from the enrichment factor between gas and liquid flows in the stripper. Formaldehyde in air samples was stripped in a stripping coil (inner diameter $2 \mathrm{~mm}$; length $120 \mathrm{~cm}$ ) with a stripping flow of $0.42 \mathrm{ml} \mathrm{min}^{-1}$ at $10^{\circ} \mathrm{C}$ and a Hantzsch reagent flow of $0.15 \mathrm{ml} \mathrm{min}^{-1}$ and a reactor temperature of $65 \pm 0.1^{\circ} \mathrm{C}$. The fluorimeter consisted of a phosphor coated mercury lamp with an excitation filter of $405 \pm 20 \mathrm{~nm}$. The detection was achieved by using a colored glass filter with a cut-off wavelength of $500 \mathrm{~nm}$ and a photomultiplier. The fluorimeter temperature was stabilized at $40 \pm 0.1^{\circ} \mathrm{C}$. The gas phase detection limit with these instrument settings was $\approx 50$ ppt. Zeroing signals were obtained by passing the ambient air through a filter cartridge containing a Hopkalit catalyst. For the span signal, liquid standards with $10^{-6} \mathrm{moll}^{-1}$ were applied to the stripping solution line. The preparation of this standard was done by dilution of a long term stable $0.01 \mathrm{moll}^{-1}$ working standard using the stripping solution for dilution. In previous experiments a positive $\mathrm{O}_{3}$ interference of $\approx 200 \mathrm{ppt} \mathrm{HCHO}$ signal for $100 \mathrm{ppb}$ of $\mathrm{O}_{3}$ was found. The interference was found to be linear and humidityindependent. A Teflon line ( $\mathrm{L}=2 \mathrm{~m}$; $\mathrm{OD}=6.35 \mathrm{~mm}$ ) was connected to one of the glass manifolds taking a sampling flow of $11 \mathrm{~min}^{-1}$ (STP) for analysis.

\subsection{Hantzsch MA-100 (iup-UB)}

A commercial, wet-chemical instrument (Methanalyser, Alpha Omega Power Technologies, Model MA-100, Albuquerque, New Mexico, USA) was deployed for HCHO measurements (Li et al., 2001; Fan and Dasgupta, 1994). The instrument consists of a Nafion-membrane diffusion scrubber integrated with an automated, liquid reactor. Air is passed through the scrubber at a constant flow rate of $11 \mathrm{~min}^{-1}$ and formaldehyde in the air diffuses through the membrane into a counter-flow of water. The aqueous HCHO then reacts with $\mathrm{NH}_{4}^{+}$and acetyl acetone (Hantzsch reaction) inside the liquid reactor forming a fluorescent product, 3,5diacetyl-1,4-dihydrolutidine (DDL), which is continuously monitored. For the experiments presented here a two-way inlet system was used to allow semi-continuous measurements of HCHO and methanol (Solomon et al., 2005). Air was sampled at a constant flow rate of $1.71 \mathrm{~min}^{-1}$ (STP) from the glass manifold via a Teflon PFA tube $(\mathrm{OD}=6.35 \mathrm{~mm})$, passed through a Teflon pump (KNF Neuberger Inc., Model N86 KTDC B, Trenton, New Jersey, USA) and directed into a 3way PFA Teflon valve (Metron Technologies, Unterschleissheim, Germany) where it was either diverted through a catalytic methanol-to-formaldehyde converter for methanol measurements or directly led to the instrument for $\mathrm{HCHO}$ measurements (Solomon et al., 2005). Gas phase HCHO calibration was performed using a permeation tube-based gas standard generator (KIN-TEK, Model $491 \mathrm{MB}$, LaMarque, Texas, USA) providing an accuracy of $8 \%$. Due to technical problems during the campaign (calibration valve malfunction) the instrument's response factors were obtained in an independent calibration after the campaign. The detection limit was $80 \mathrm{ppt}$ at an integration time of $120 \mathrm{~s}$. 


\subsection{DNPH-HPLC (ift)}

HCHO collection was performed by using self-prepared glass cartridges $(\mathrm{L}=100 \mathrm{~mm} ; \mathrm{OD}=10 \mathrm{~mm})$ filled with $\approx 1 \mathrm{~g}$ silica gel (Merck, Darmstadt; sphere diameter: $125-200 \mu \mathrm{m}$ ) spiked with phosphoric acid and 2,4-dinitrophenylhydrazine (DNPH) (Müller, 1997). The glass cartridges were located between two stainless steel valves in an automatic multichannel sampler. A quartz fibre particle filter was installed in front of the sampler to prevent contamination of the valves. The air flow through the cartridges was regulated by a mass flow controller to $21 \mathrm{~min}^{-1}$ (STP). A collection efficiency of 95-100\% was found for similar cartridges in previous studies (Slemr, 1991; Zhang et al., 1994) and verified by laboratory experiments. At the sampler inlet a copper tube coil $(\mathrm{L}=1 \mathrm{~m} ; \mathrm{ID}=4 \mathrm{~mm})$ impregnated with potassium iodide $(\mathrm{KI})$ was used as an $\mathrm{O}_{3}$ scrubber to prevent the occurrence of $\mathrm{O}_{3}$ artifacts (Arnts and Tejada, 1989). In earlier studies with $\mathrm{O}_{3}$ levels of $100 \mathrm{ppb}$, an $\mathrm{O}_{3}$ removal efficiency $>99 \%$ was measured for the scrubber. The cartridge sampler was connected to the glass sample manifold via a Teflon PTFE tube $(\mathrm{L}=2 \mathrm{~m} ; \mathrm{OD}=6.35 \mathrm{~mm}$ ). Sampling times ranged from $60 \mathrm{~min}$ to $120 \mathrm{~min}$. One cartridge of the sampler was not exposed to chamber air but handled identically to a sample to serve as a blank. HPLC analysis was carried out using a ternary gradient HPLC-system equipped with a temperature controlled column holder (Thermoquest, AS3000) and a multiwavelength fast scanning UV/VIS detector (Thermoquest, UV3000HR). The analytical column in use was a WATERS RP18 $(300 \times 3.9 \mathrm{~mm}, 4 \mu \mathrm{m}, 60 \AA)$. The separation was carried out at $45^{\circ} \mathrm{C}$ and a solvent flow rate of $1.5 \mathrm{ml} \mathrm{min}^{-1}$. The detection wavelengths were set to 360 and $380 \mathrm{~nm}$. A threepoint calibration using a liquid gravimetric standard was carried out (accuracy is 15\%). The detection limit of the method is $40 \mathrm{ppt}$.

\subsection{BB-DOAS (ICG-FZJ)}

Differential Optical Absorption Spectroscopy (DOAS) is a direct and non-extractive method based on the BeerLambert law. The atmosphere simulation chamber SAPHIR is equipped with a Broadband-DOAS system (Bossmeyer et al., 2006; Brauers et al., 2007). A Xenon short arc lamp (OSRAM, XBO 75W/2) serves as a light source and is housed outside the chamber. The light is transferred to the chamber via mirrors and an optical fibre. During the intercomparison campaign, an edge filter (Schott, U-330) was used to prevent excess light from entering the spectrograph. The light enters and leaves the chamber through a quartz window. Inside the chamber the light travels 48 times within a modified version of a White type multiple reflection system of $20 \mathrm{~m}$ base length. The optical components of the White cell are integrated at the north and south end. After passing the White cell, the light is guided via an optical fibre assembly into a Czerny-Turner type spectrograph (Jobin Yvon,
HR 460) equipped with a blazed holographic grating. There it is dispersed and projected onto a photo diode array (Hamamatsu, S3904) with 1024 pixels covering a wavelength range of $44 \mathrm{~nm}$. The spectral resolution is $0.17 \mathrm{~nm}$ full width at half maximum. Data are acquired through a controller (Hoffmann Messtechnik, Rauenberg, Germany) connected to a PC. During this intercomparison exercise $\mathrm{HCHO}$ was detected in the spectral range from 310 to $350 \mathrm{~nm}$ using a $960 \mathrm{~m}$ light path inside SAPHIR. For the evaluation of the spectra we used the cross section of Meller and Moortgat (2000) as described in Brauers et al. (2007). The accuracy was $6 \%$ with an additional uncertainty in the temperature coefficient (Brauers et al., 2007). The 1- $\sigma$ precision of the measurements presented here was in the order of $400 \mathrm{ppt}$.

\subsection{PTR-MS (IAP-LFUI)}

A commercial PTR-MS instrument (PTRMS-FDT-s, Ionicon Analytik GmbH, Innsbruck, Austria) was used for $\mathrm{HCHO}$ measurements. PTR-MS is a chemical ionization technique based on proton-transfer reactions from $\mathrm{H}_{3} \mathrm{O}^{+}$primary ion to gaseous organic analytes (Lindinger et al., 1999) with a higher proton affinity than $\mathrm{H}_{2} \mathrm{O}$. The PTR-MS was run in the selected ion monitoring (SIM) mode with a single ion dwell time of $2 \mathrm{~s}$ and a total SIM cycle time of $75 \mathrm{~s}$. Protonated $\mathrm{HCHO}$ was measured at $m / z=31$. In order to optimize the performance of the PTR-MS instrument for HCHO measurements the PTR-MS experimental set-up and operational parameters were slightly modified (Wisthaler et al., 2006). Under standard operating conditions the backward reaction of protonated $\mathrm{HCHO}$ with water significantly reduces the instrument's sensitivity to HCHO resulting in a detection limit in the low-ppb range (for details see Karl et al., 2003; Steinbacher et al., 2004). The length of the Teflon PFA tube $(\mathrm{OD}=6.25 \mathrm{~mm})$ through which the ion source is evacuated was shortened to $\approx 6 \mathrm{~cm}$ to maximize the water pump-down from the ion source. This simple modification reduced the water leakage from the ion source into the drift tube to $<0.1 \%$. Given that the absolute humidity in the analyte air is also low $(<1 \%)$ the drift field needed to prevent hydration of ions can be greatly reduced leading to an increase in sensitivity due to an increased ion residence time. In this study the PTR-MS operating parameters were reduced from typical values ranging from $\approx 130 \mathrm{Td}$ $\left(1 \mathrm{Td}=10^{-17} \mathrm{~cm}^{2} \mathrm{~V}\right.$ molecule $\left.{ }^{-1}\right)$ to $75 \mathrm{Td}$. Lowering the $\mathrm{E} / \mathrm{N}$ levels also reduces the rate of the collision-energy driven backward reaction between protonated $\mathrm{HCHO}$ and water resulting in an additional sensitivity gain. The simple optimizations lead to the following PTR-MS performance characteristics for HCHO: detection limit: $0.15-0.25 \mathrm{ppb}(2-\sigma, 2 \mathrm{~s}$ signal integration time, for the humidity levels studied herein); precision $10-15 \%$ (at $1 \mathrm{ppb}$ ).

Accurate HCHO gas-phase calibration using a permeation-tube-based gas standard generator (KINTEK, Model 491 MB LaMarque, Texas, USA) turned out 
to be problematic. PTR-MS HCHO calibration factors obtained during two successive days following identical calibration procedures differed by $40 \%$. Calibration procedures involved online monitoring of the $m / z=31$ signal after connection of the standard generator to the PTR-MS instrument until a stable mean value was reached $(2-3 \mathrm{~h})$. The observed within-run precision (30 data points collected in $300 \mathrm{~s}, 5 \mathrm{~s}$ signal integration on $\mathrm{m} / \mathrm{z}=31$ and $5 \mathrm{~s}$ integration time for other signals) was in the range of 8 -to-9\% even when the mean signal was stable. PTR-MS precision derived from counting statistics on the observed count rates was less than $0.5 \%$ indicating that the variability was caused by fluctuations in the standard generator output. Given the observed deficits, no further PTR-MS investigations with the permeation-tube-based gas standard generator were carried out (nor were any of the other HCHO monitors used to resolve the discrepancies) and PTR-MS response factors for $\mathrm{HCHO}$ were obtained by two alternative methods: (1) by calculation using simple pseudo first-order ion-molecule reaction kinetics (Sprung et al., 2001) and (2) by using acetaldehyde $\left(\mathrm{CH}_{3} \mathrm{CHO}\right)$ as a surrogate for $\mathrm{HCHO}$. An acetaldehyde calibration was obtained by dynamic dilution from a certified gas standard (Apel-Riemer Environmental Inc., Denver, Colorado, USA). A slightly different mass discrimination in the MS detection system and different electrical properties (dipole moment, molecular polarizability) of $\mathrm{HCHO}$ and $\mathrm{CH}_{3} \mathrm{CHO}$ were taken into account. Response factors of both calibration procedures were in good agreement $( \pm 10 \%)$. The PTR-MS instrument was connected to the main sampling manifold through a $2 \mathrm{~m}$ long Teflon PFA tube $(\mathrm{OD}=3.175 \mathrm{~mm})$ pumped at a flow rate of $250 \mathrm{~cm}^{3} \mathrm{~min}^{-1}$ (STP). A flow of $\approx 150 \mathrm{~cm}^{3} \mathrm{~min}^{-1}$ was branched off to the inlet of the PTR-MS instrument, which consisted of a $1 \mathrm{~m}$ long pressure-controlled Silcosteel (Restek Corp., Bellefonte, PA, USA) capillary (OD=0.39 mm). An effective sample flow of $\approx 20 \mathrm{~cm}^{3} \mathrm{~min}^{-1}$ was supplied to the PTR-MS drift tube, with the overflow being discarded. All inlet lines were heated to $60^{\circ} \mathrm{C}$. To determine the instrumental background signals the sample flow was periodically diverted through a VOC scrubber (platinum coated quartz wool, $T=350^{\circ} \mathrm{C}$ ) capable of removing VOCs with an efficiency $>99.9 \%$.

\section{Experimental}

\subsection{Atmosphere Simulation Chamber SAPHIR}

The atmosphere simulation chamber SAPHIR consists of an almost cylindrical, double-wall Teflon FEP (DuPont) tube held in a steel frame. The inner tube $(r=2.5 \mathrm{~m}, L=18 \mathrm{~m})$ is used as a reactor for simulation experiments (e.g. Rohrer et al., 2005; Bossmeyer et al., 2006; Wegener et al., 2007; Brauers et al., 2007). The volume of the reactor is $268 \pm 5 \mathrm{~m}^{3}$, with a volume-to-surface ratio of about $0.8 \mathrm{~m}$. The space be- tween the inner and outer tube is $\approx 0.2 \mathrm{~m}$. This interstitial space is continuously flushed with ultra-pure synthetic air to prevent diffusion and permeation of trace gases from outside into the reactor. The pressure of the inner chamber is always held at a pressure of $60 \mathrm{~Pa}$ above ambient. The wall of the inner tube consists of FEP film with a thickness of $125 \mu \mathrm{m}$ except for the floor $\left(52 \mathrm{~m}^{2}\right)$ which is made of a $500 \mu \mathrm{m}$ FEP film. The outer tube consists of a $250 \mu \mathrm{m}$ FEP film. The reactor is covered by a movable, opaque roof construction, which can be opened to perform experiments with sunlight illumination. The experiments presented here were performed under dark conditions.

Before experiments were started, the chamber was flushed with synthetic air of high purity $\left(\mathrm{N}_{2}: \mathrm{O}_{2}=79: 21\right.$; high purity (7.0, equivallent to $99.99999 \%$ ) for both $\mathrm{N}_{2}$ and $\mathrm{O}_{2}$; obtained from headspace of liquid $\mathrm{N}_{2}$ and liquid $\mathrm{O}_{2}$, respectively) which in the following is referred to as "zero air". Flushing was carried out at a flow rate of $300 \mathrm{~m}^{3} \mathrm{~h}^{-1}$ for several hours to purge all trace impurities below the detection limits of the instruments. During flushing the water vapor pressure was reduced to levels of less than $0.1 \mathrm{hPa}$, corresponding to a dewpoint lower than $-40^{\circ} \mathrm{C}$.

During the intercomparison exercise the analytical instruments continuously withdrew air from the chamber. Also gas is lost through unavoidable small leaks in the FEP film of the chamber wall. These losses are compensated by adding zero air $\left(3-10 \mathrm{~m}^{3} \mathrm{~h}^{-1}\right)$ through a separate inlet line to the chamber (replenishment flow) to keep the air volume and pressure inside the chamber constant. Consequently, the HCHO mixing ratio in the chamber was diluted by this process. Inside the chamber a powerful fan is installed which provides mixing of injected gases in less than $2 \mathrm{~min}$. The fan was always switched on when trace gases or water was added.

Ozone $\left(\mathrm{O}_{3}\right)$ was generated using a silent discharge ozonizer (Ozat CFS-1A, Ozonia AG, Dübendorf, Switzerland) supplied with high purity $\mathrm{O}_{2}$ to minimize the formation of aldehydes, $\mathrm{NO}_{\mathrm{x}}$, and organic radicals. The $\mathrm{O}_{2} / \mathrm{O}_{3}$ mixture was added to the replenishment flow which ensured rapid mixing of $\mathrm{O}_{3}$ in the chamber when the fan is on. $\mathrm{O}_{3}$ mixing ratios were monitored by a UV absorption instrument (ANSYCO GmbH, model O3-41M, Karlsruhe, Germany).

Water vapor mixing ratios in the chamber air were adjusted by injection of water steam into the flushing air stream. Ultrapure $\mathrm{H}_{2} \mathrm{O}$ (Milli-Q, Millipore) was stored in a reservoir vessel with high-purity $\mathrm{N}_{2}$ being continuously bubbled through the water column to remove any dissolved trace gases. The clean $\mathrm{H}_{2} \mathrm{O}$ was vaporized and transferred into the SAPHIR chamber with a flow of zero air. Humidity in the chamber was determined with a frost point hygrometer (General Eastern, model Hygro M4, General Electric Corp., Fairfield, Connecticut). 

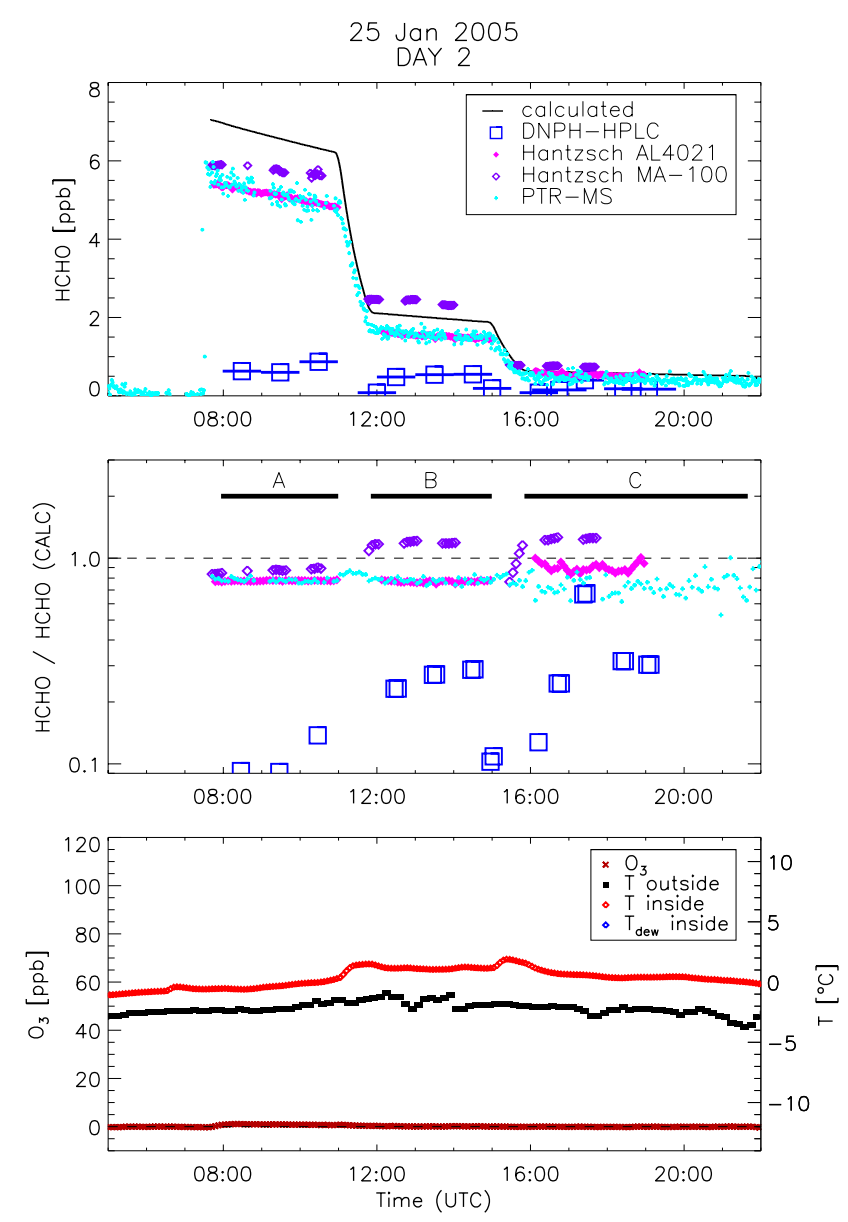

Fig. 2. Time series of measured and calculated HCHO mixing ratios and chamber conditions during the zero air experiment. Upper panel: Original measurements of the individual instruments at their original time resolution. The calculated values are at $1 \mathrm{~min}$ time-step. Middle panel: Measurements ratioed to $\mathrm{HCHO}_{\text {calc }}$ in log-scale. Lower panel: Ozone mixing ratio (left axis) and temperatures (right axis) outside the chamber and inside the chamber. The dewpoint temperature is not visible since it was at $-45^{\circ} \mathrm{C}$.

\subsection{Setup of the formaldehyde instruments at SAPHIR}

Chamber air was drawn at a flow rate of $41.0 \pm 0.51 \mathrm{~min}^{-1}$ through a heated $\left(60-65^{\circ} \mathrm{C}\right)$ Teflon PTFE line $(L=40 \mathrm{~m}$; $\mathrm{ID}=10 \mathrm{~mm}$ ) from the floor of the SAPHIR chamber to six laboratory containers situated below the chamber. In each container a heated glass manifold was installed where the inlet lines of the individual instruments were connected to (Fig. 1). Possible leakages in the sampling line were monitored by a $\mathrm{CO}_{2}$ sensor (GMM222, Vaisala, Finland) placed at the end of the main inlet. The zero air in the chamber did not contain $\mathrm{CO}_{2}$ so that leaks would have been rapidly detectable.

\subsection{Formaldehyde injection}

Gas-phase HCHO was generated by thermolysis of a weighted amount of para-HCHO powder (Merck; purity $>95 \%$ ) in an external glass reactor similar to the procedure described in Brauers et al. (2007). During heating the reactor was flushed with a constant flow of high-purity $\mathrm{N}_{2}$ which transferred the gas-phase $\mathrm{HCHO}$ into the chamber. The $\mathrm{HCHO}$ mixing ratio in the chamber after injection, $\mathrm{HCHO}_{\text {inj }}$, was derived from the known chamber volume $V$ and the amount of HCHO injected. However, the transfer line (Teflon PFA, $L=4 \mathrm{~m}$; OD=6 mm) was not heated and thus at sub-zero ambient temperature. Therefore, the calculation of the initial $\mathrm{HCHO}$ mixing ratios in the chamber is less accurate than described in Brauers et al. (2007). However, if HCHO losses occurred in the inlet the calculated mixing ratio is only an upper limit for the true value.

The HCHO mixing ratio-time-profile in the chamber was calculated from the volume $V$, the injected formaldehyde $\mathrm{HCHO}_{\text {inj }}$ and the replenishment flow rate $F(t)$ using equation

$\mathrm{HCHO}_{\text {calc }}(t)=\mathrm{HCHO}_{\text {inj }} \times \exp \left(-\int_{0}^{t} F\left(t^{\prime}\right) / V d t^{\prime}\right)$

with a 1 min time step. Injected amounts of $\mathrm{HCHO}$ and dilution were known only to the independent referee of the intercomparison exercise.

\subsection{Experiment}

The HCHO intercomparison exercise presented here took place 24-28 January 2005. HCHO instruments were intercompared on five successive days with different experimental conditions.

On day 1 (24 Jan 2005), a blank experiment was conducted without $\mathrm{HCHO}$ being injected into the chamber. The chamber was initially filled with dry zero air; $\mathrm{H}_{2} \mathrm{O}$ and $\mathrm{O}_{3}$ were sequentially added during the course of the day to investigate potential $\mathrm{HCHO}$ formation and interferences. Because of a number of technical problems associated with both individual instruments and manifold leaks in the laboratory containers, no data are reported for this day.

On day 2 (25 Jan 2005), HCHO was spiked into dry zero air. On day 3 (26 Jan 2005), the sample air matrix onto which $\mathrm{HCHO}$ was spiked was humidified zero air. On day 4 (27 Jan 2005), both $\mathrm{H}_{2} \mathrm{O}$ and $\mathrm{O}_{3}$ were added to the chamber prior to $\mathrm{HCHO}$ injection. In order to challenge the instruments with different levels of $\mathrm{HCHO}$, the spiked sample air matrix was diluted with zero air twice during days 2,3 and 4 . Consequently, each of the respective days consisted of three $3 \mathrm{~h}$ sampling intervals labelled A, B, and C (see Figs. 2, 3 and 4).

The additional dilution steps were included in the calculation of $\mathrm{HCHO}_{\text {calc }}(t)$. The degree of dilution was known only to the independent referee. Investigated HCHO mixing ratios varied from tenths of a ppb to less than $10 \mathrm{ppb}$; 
this range was known to the participants. In order to maintain $\mathrm{H}_{2} \mathrm{O}$ and $\mathrm{O}_{3}$ levels approximately constant throughout an entire day, compensation injections were made during the major dilution steps.

On day 5 (28 Jan 2005), the chamber was flushed with particulate-filtered ambient air for $3 \mathrm{~h}$ (see Fig. 5). The purpose of this experiment was to challenge the instruments with low HCHO levels present in wintertime Jülich boundarylayer air. After a sampling interval of $2 \mathrm{~h}$, this real-world matrix was spiked with $\mathrm{HCHO}$ and monitored by the instruments for another $3.5 \mathrm{~h}$.

\section{Results and discussion}

For comparison analysis, we produced multiple graphs for each day of the intercomparison exercise with the exception of day 1 for reasons given above. In the lower panel of the multiple graphs (Figs. 2, 3, 4, and 5), the time series of experimental conditions $\left(\mathrm{O}_{3}\right.$ mixing ratio, $T_{\text {outside }}$ temperature outside of the chamber, $T_{\text {inside }}$ temperature inside the chamber, and $T_{\text {dewp }}$ dewpoint temperature inside) are displayed. The upper panel of each figure shows the experimentally derived $\mathrm{HCHO}$ mixing ratios together with the calculated mixing ratio-time profile $\mathrm{HCHO}_{\text {calc }}(t)$. Experimental data were not corrected after submission to the referee with two exceptions in the case of the Hantzsch MA-100 analyzer. During day 3 an obvious time conversion error had occurred during data processing and a time correction was necessary. In addition, during day 5 (level B) a series of outliers $(n=14)$ in the 3 to $5 \mathrm{ppb}$ range were removed which were caused by a leaking valve between the calibration gas stream and the analyte gas stream.

The middle panel displays the ratios of measured-tocalculated $\mathrm{HCHO}$ mixing ratios in the chamber versus time. Table 2 summarizes these ratios for each experimental condition and each instrument. As mentioned above injections at low temperatures were less accurate, resulting in less accurate $\mathrm{HCHO}_{\text {calc }}(t)$ values. Therefore, the observed ratios were lower than 1 on day 2 and 3 while on day 4 higher ratios were observed. The dilution factors during levels A, B and $\mathrm{C}$ and in the transitions from level $\mathrm{A}$ to level $\mathrm{B}$ and from level B to level C, respectively, were determined with high accuracy. Consequently, a time-constant ratio of measuredto-calculated HCHO levels was used as an indicator for the linearity of the instrumental response and the constancy of an eventual instrumental offset. This was valid as long as external injection was the only source of $\mathrm{HCHO}$ and dilution was the only sink for HCHO in the chamber. The middle panel figures give most of the information which is typically contained in linear regression plots used for comparison analysis. We have thus refrained from presenting additional regression plots.

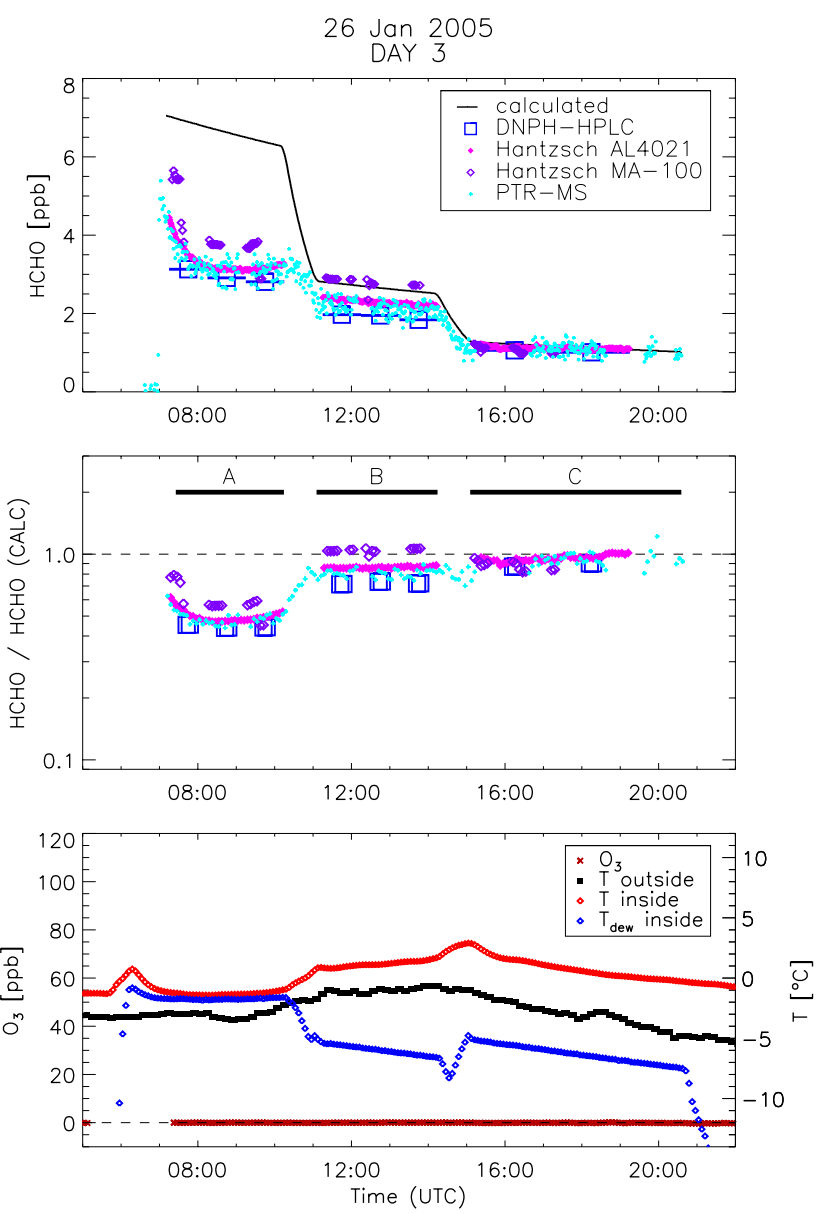

Fig. 3. Time series of measured and calculated $\mathrm{HCHO}$ mixing ratios and chamber conditions during the zero air experiment with humidity. Upper panel: Original measurements of the individual instruments at their original time resolution. The calculated values are at 1 min time-step. Middle panel: Measurements ratioed to $\mathrm{HCHO}_{\text {calc }}$ in log-scale. Lower panel: Ozone mixing ratio (left axis) and temperatures (right axis) outside the chamber, inside the chamber, and dewpoint temperatures inside.

\subsection{Day 2 (dry zero air)}

$\mathrm{HCHO}_{\text {inj }}$ was at least $20 \%$ higher than all experimentally derived $\mathrm{HCHO}$ mixing ratios at the start of the experiment. This indicates possible transfer losses when $\mathrm{HCHO}$ was flushed into the chamber. Since the BB-DOAS system did not measure during day 2 (due to technical problems), no in-situ chamber measurement was obtained. However, the relative diurnal profile of the calculated concentration is known with high accuracy (Eq. 1).

The data produced by the Hantzsch AL4021 and the PTRMS instruments were in excellent agreement during day 2 (Fig. 2, top). The larger scatter of the PTR-MS data reflects its higher statistical error at the chosen $2 \mathrm{~s}$ signal integration 

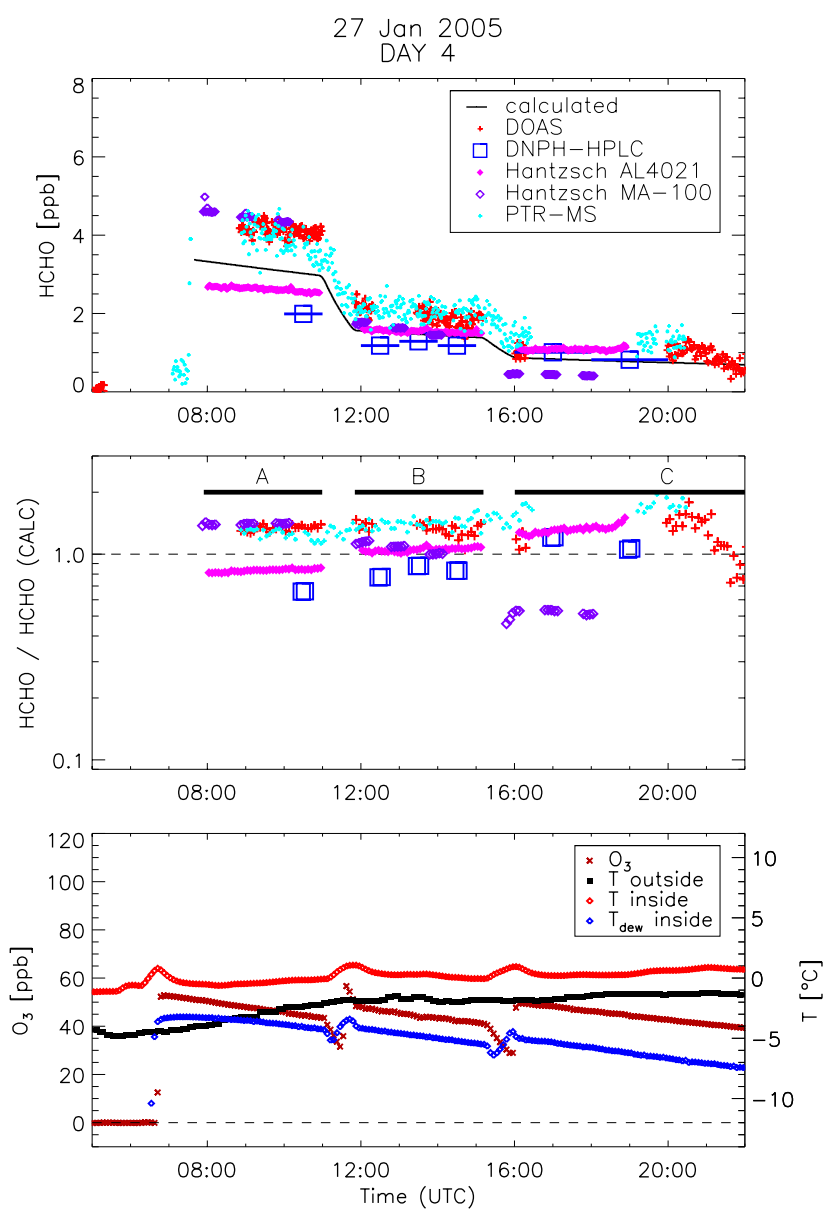

Fig. 4. Time series of measured and calculated HCHO mixing ratios and chamber conditions during the zero air experiment with humidity and ozone. Upper panel: Original measurements of the individual instruments at their original time resolution. The calculated values are at 1 min time-step. Middle panel: Measurements ratioed to $\mathrm{HCHO}_{\text {calc }}$ in log-scale. Lower panel: Ozone mixing ratio (left axis) and temperatures (right axis) outside the chamber, inside the chamber, and dewpoint temperatures inside.

time; the Hantzsch AL4021 analyzer produced 60 s time averages. At level $\mathrm{C}$ a small discrepancy of $\approx 0.1 \mathrm{ppb}$ between the two instruments was observed. While the ratios $\mathrm{HCHO}_{\mathrm{PTR}-\mathrm{MS}} / \mathrm{HCHO}_{\text {calc }}$ and $\mathrm{HCHO}_{\mathrm{AL} 4021} / \mathrm{HCHO}_{\text {calc }}$ remained constant throughout levels A and B (Fig. 2, middle), $4 \%$ lower ratios were observed for PTR-MS at level C while the ratios of Hantzsch AL4021 analyzer increased by $10 \%$ suggesting that this instrument was affected by a positive bias on the order of $0.1 \mathrm{ppb}$.

The Hantzsch MA-100 data were substantially higher than the data produced by both the Hantzsch AL4021 analyzer and the PTR-MS instrument. Notably, the ratio $\mathrm{HCHO}_{\mathrm{MA}-100} / \mathrm{HCHO}_{\text {calc }}$ changed from $<1$ (level A) to $>1$ (level B and C). The discrepancy with the other instruments may thus not be simply explained by a constant offset or a calibration curve error. While we cannot exclude the possibility of an instrumental problem of the MA-100 analyzer, we consider it more likely that the modified inlet system biased the measurements. The sample flow for this instrument was pumped through a Teflon diaphragm pump prior to analysis. Previous studies have shown that these pumps release $\mathrm{C}_{2}-\mathrm{C}_{4}$ aldehydes in significant amounts (Apel et al., 2003) as aldehydes permeate from the pumps into the sample air stream. Even though Apel et al. (2003) did not measure $\mathrm{HCHO}$ in their experiments we consider it very likely to be the case also for the $\mathrm{C}_{1}$ aldehyde. $\mathrm{HCHO}$ carry-over from the methanol-to-HCHO converter and an occasional valve malfunction (as observed later) leading to leakage from the HCHO calibration channel into the sample air channel were other possible failure scenarios associated with the inlet system.

The DNPH-HPLC data severely underestimated HCHO levels during the entire day 2 . This can be simply explained by the fact that hydrazine-to-hydrazone conversion is greatly suppressed at low humidities. This phenomenon has not been studied in detail for $\mathrm{HCHO}$ but tests conducted with acetone, propanal and diethylketone test atmospheres at the ift laboratories revealed that below 5\% RH the hydrazone yield was only $5-35 \%$ of the yield observed at $40 \% \mathrm{RH}$. The applied DNPH-HPLC method is thus obviously not suited for HCHO measurements at low humidities.

\subsection{Day 3 (humid zero air)}

After flushing the chamber over night with zero air, water was injected into the chamber from 5:45 to 6:10 (Fig. 3, bottom). The PTR-MS instrument was the only analyzer that sampled the humidified air matrix for a period of $\approx 25 \mathrm{~min}$ before $\mathrm{HCHO}$ injection. The obtained data indicate that no $\mathrm{HCHO}$ was introduced in the chamber during the humidification step.

While $\mathrm{HCHO}_{\text {inj }}$ was $7.05 \mathrm{ppb}$, all measured $\mathrm{HCHO}$ values show a rapid initial decay by more than a factor of 2 indicating a strong loss of $\mathrm{HCHO}$ in the chamber during phase A. During this phase the dew point temperature inside the chamber was in the range of $-1^{\circ} \mathrm{C}$ to $-2^{\circ} \mathrm{C}$. This was between the measured temperatures outside and inside the chamber (Fig. 3, bottom). As a consequence, water condensation was visibly observed on the FEP foil of the chamber and gas-phase $\mathrm{HCHO}$ was scavenged into the liquid phase. This effect, reflecting the high solubility of $\mathrm{HCHO}$, was not observed in simultaneous measurements of other compounds like alcohols and higher aldehydes (Apel et al., 2008 ${ }^{1}$ ).

Notably, most of the scavenged HCHO was released back into the gas phase when the chamber was flushed with dry air during the transition from level A to level $\mathrm{B}$. When going from level $\mathrm{B}$ to level $\mathrm{C}$ a further minor recovery of $\mathrm{HCHO}$ was observed. For level C, calculated and measured $\mathrm{HCHO}$ values were in excellent agreement indicating that no 
injection losses occurred during day 3. In humidified air the agreement between Hantzsch AL4021 and PTR-MS data was again excellent. The DNPH-HPLC data were also in good agreement, although $\approx 0.2-0.3 \mathrm{ppb}$ lower during levels $\mathrm{A}$ and B.

The Hantzsch MA-100 data were again affected by a nonconstant $\mathrm{HCHO}$ offset leading to an overestimation of $\mathrm{HCHO}$ mixing ratios during levels $\mathrm{A}$ and level $\mathrm{B}$. However, for level $\mathrm{C}$ agreement with the other instruments was good. The BBDOAS system measured only at different wavelengths (Apel et al., $2008^{1}$ ).

\subsection{Day 4 (humid zero air with ozone)}

Again after flushing overnight, $\mathrm{H}_{2} \mathrm{O}$ and $\mathrm{O}_{3}$ were both injected into the chamber from 5:55 to 6:36 and at 6:43, respectively. The PTR-MS instrument was again the only analyzer that sampled the humidified and ozonized air matrix before $\mathrm{HCHO}$ injection. A HCHO mean value of $0.52 \pm 0.17 \mathrm{ppb}$ was measured for the period 7:05 to 7:35. This finding indicates that traces of $\mathrm{HCHO}$ were already present in the chamber before $\mathrm{HCHO}$ injection, most likely due to formation during the $\mathrm{O}_{3}$ generation/injection process and/or heterogeneous $\mathrm{O}_{3}$ reactions on the chamber walls. Here we will briefly refer to results from day 1 which have otherwise been excluded from the analysis. The PTR-MS instrument was operational when $\mathrm{O}_{3}$ was added to humidified air during day 1 . A careful investigation of the data obtained in the $3 \mathrm{~h}$ monitoring period after $\mathrm{O}_{3}$ addition indicated that the observed relative changes were not affected by manifold leaks. After $\mathrm{O}_{3}$ addition, the PTR-MS analyzer detected an immediate $\mathrm{HCHO}$ increase by 0.2 to $0.3 \mathrm{ppb}$ (all the other monitored $\mathrm{C}_{2}-\mathrm{C}_{10}$ aldehydes increased as well). During the first hour after $\mathrm{O}_{3}$ addition HCHO levels increased to a maximum level of $\approx 0.4 \mathrm{ppb}$ followed by a $0.1 \mathrm{ppb}$ decrease in the $2 \mathrm{~h}$ thereafter. We thus conclude that a time-varying additional $\mathrm{HCHO}$ source has to be considered whenever $\mathrm{O}_{3}$ is present in the chamber. All instruments (with the exception of the Hantzsch MA-100) show an increase in the measured-to-calculated HCHO levels during day 4 (Fig. 4, middle). This may be explained by the fact that the calculated values do not consider the additional $\mathrm{HCHO}$ from the three $\mathrm{O}_{3}$ additions (one primary injection, 2 compensation injections). For level A, measurements of DOAS, PTR-MS and Hantzsch MA-100 were in close agreement. Taking into account a 0.5 to $0.8 \mathrm{ppb}$ offset due to $\mathrm{HCHO}$ formation from the $\mathrm{O}_{3}$ injection the calculated values were close to the values reported by these instruments. This finding again indicates that no injection losses occurred on day 4. However, two other instruments, the Hantzsch AL4021 and the DNPH-HPLC, reported significantly lower values at the highest $\mathrm{H}_{2} \mathrm{O}$ and $\mathrm{O}_{3}$ mixing ratios and it is not a priori clear which set of instruments is in error. Based on the assumption that a positive ozone interference can be excluded with high confidence for the DOAS system we concluded that the Hantzsch AL4021 was affected by a negative

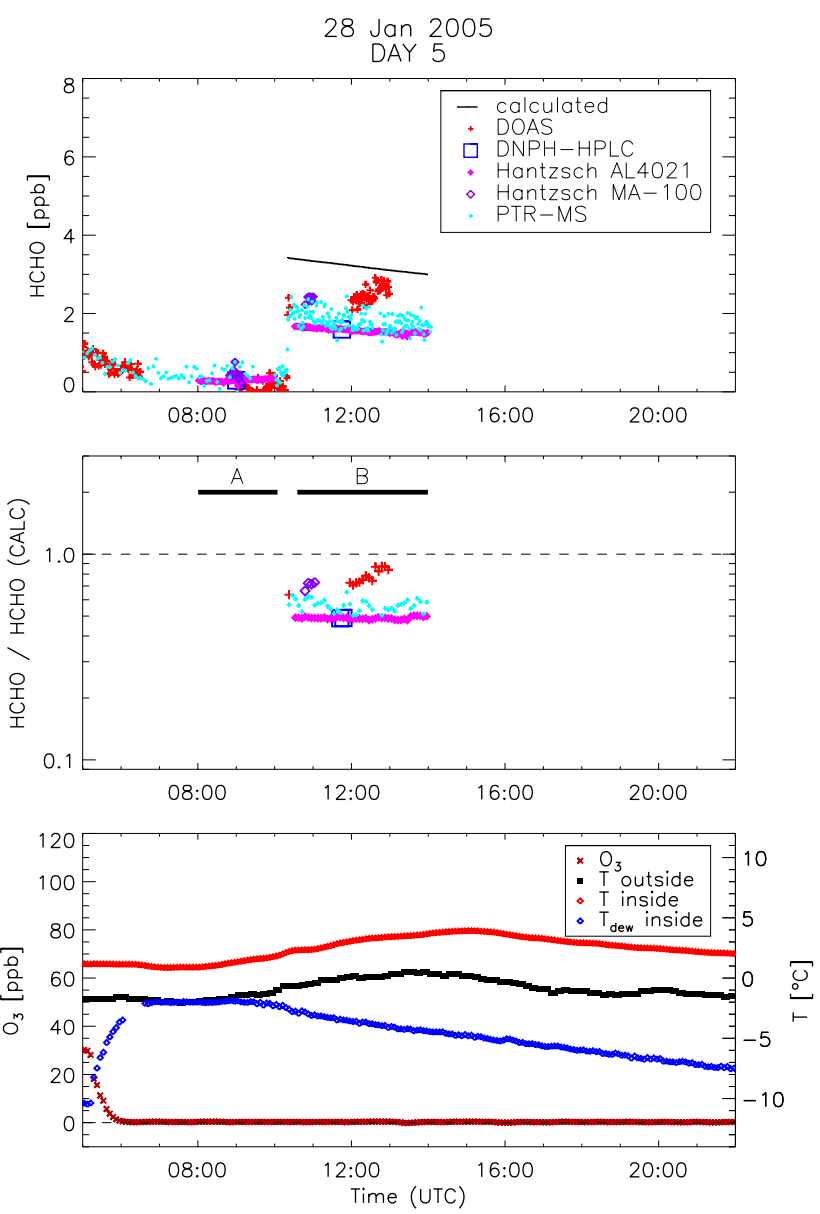

Fig. 5. Diurnal profiles of the HCHO measurements and chamber data during the ambient air experiment. Upper panel: Original measurements of the single instruments at their original time resolution. The calculated values are at 1 min time-step. Middle panel: Measurements ratioed to the $\mathrm{HCHO}_{\text {calc }}$ in log-scale. Lower panel: Ozone mixing ratio (left axis) and temperatures (right axis) outside, inside, and dewpoint.

ozone interference. This result is difficult to explain, as for this method no negative ozone bias has been reported so far. Successive intensive laboratory tests to investigate this phenomenon yielded a positive bias of $200 \mathrm{ppt} \mathrm{HCHO}$ at $100 \mathrm{ppb}$ $\mathrm{O}_{3}$. In consequence, at present we have no sound explanation for the observed negative bias.

The DNPH-HPLC data were somehow too low for level $\mathrm{A}$ and $\mathrm{B}$ but in quite good agreement for level C. A KI $\mathrm{O}_{3}$ scrubber was placed upstream the DNPH cartridges to prevent any negative $\mathrm{O}_{3}$ bias. The findings would be explainable by a varying performance of the KI ozone scrubber. It is known that these devices need water for efficient scrubbing and initially it may not have been well-conditioned with water. However, ozonide peaks which are usually observed in the chromatograms when $\mathrm{O}_{3}$ breaks through, were not 
Table 2. Performance of the instruments during synthetic air matrix experiments. The results are presented as the ratio of measured to calculated concentrations for the individual days 2-4 and different concentration levels A-C.

\begin{tabular}{|c|c|c|c|c|c|c|c|c|c|c|}
\hline \multirow[b]{2}{*}{ \# } & \multirow[b]{2}{*}{ Instrument } & \multicolumn{3}{|c|}{ Day 2 (dry) } & \multicolumn{3}{|c|}{ Day 3 (humid) } & \multicolumn{3}{|c|}{ Day $4\left(\text { humid }+\mathrm{O}_{3}\right)^{2}$} \\
\hline & & A & B & $\mathrm{C}$ & $\mathrm{A}^{1}$ & B & $\mathrm{C}$ & A & B & $\mathrm{C}$ \\
\hline 1 & Hantzsch AL4021 & 0.78 & 0.77 & 0.90 & 0.49 & 0.86 & 0.95 & 0.83 & 1.05 & 1.32 \\
\hline 2 & Hantzsch MA-100 & 0.88 & 1.19 & 1.25 & 0.59 & 1.04 & 0.88 & 1.40 & 1.08 & 0.52 \\
\hline 3 & DNPH-HPLC & 0.11 & 0.26 & 0.38 & 0.44 & 0.72 & 0.89 & 0.66 & 0.83 & 1.14 \\
\hline 4 & BB-DOAS & - & - & - & - & - & - & 1.33 & 1.33 & 1.28 \\
\hline 5 & PTR-MS & 0.78 & 0.78 & 0.74 & 0.48 & 0.80 & 0.93 & 1.25 & 1.41 & 1.70 \\
\hline
\end{tabular}

${ }^{1} \mathrm{HCHO}$ loss in the chamber possibly induced by water condensation. For details see text.

${ }^{2} \mathrm{O}_{3}$ induced $\mathrm{HCHO}$ formation, details are given in the text.

observed so that this hypothesis is unlikely. Currently we have no explanation for the observed negative $\mathrm{O}_{3}$ interference. Day 4 was the first day the DOAS system participated in the intercomparison for HCHO. The agreement between DOAS and PTR-MS data is remarkably good for all three levels. This is noteworthy as data from two instruments that require no external calibration, one a true in-situ instrument and the other an inlet-based sensor, agree very well. The MA-100 data again showed a strange behavior. Contrary to the other instruments the measured-to-calculated ratio decreased with time. For level C, the instrument which usually overestimated HCHO levels, produced values that are significantly lower than those reported by the other four instruments.

\subsection{Day 5 (ambient air)}

Flushing of the chamber with particulate-filtered ambient air (flow rate $\approx 500 \mathrm{~m}^{3} \mathrm{~h}^{-1}$ ) started at 05:00 and lasted until 08:00. Before flushing the chamber was filled with the sample air matrix prepared for day 4. The HCHO decay from level $\mathrm{C}$ of day 4 to ambient levels of the wintertime Jülich boundary layer was monitored only by the DOAS system and the PTR-MS instrument. Data from both instruments were in excellent agreement as can be seen in Figure 5 (top). On the morning of day 5 (05:00-09:25) the PTR-MS instrument was operated in the full scan mode with an upper mass limit of $m / z=150$. Many PTR-MS signals increased when ambient air was introduced into the SAPHIR chamber confirming the complexity of this new air matrix to be investigated. The series of $\mathrm{C}_{6}-\mathrm{C}_{10}$ aromatics was clearly discernible in the PTRMS spectrum indicating that the sampled air was strongly impacted by the morning traffic. Most of the observed PTRMS signals reached a steady-state level between 06:00 and 07:00. Level A of day 5 was sampled from 08:00 to 10:20. Wintertime ambient HCHO mixing ratios were only a few hundred ppt which is close to the BB-DOAS and PTR-MS detection limits for the signal integration times used here.
The mean value $( \pm 1-\sigma)$ over the entire period A was calculated to better compare the results of the five instruments. Results were: $0.29 \pm 0.04$ (Hantzsch AL4021), $0.29 \pm 0.10$ (DNPH-HPLC), $0.09 \pm 0.18$ (BB-DOAS), $0.44 \pm 0.19$ (PTRMS), $0.45 \pm 0.14$ (Hantzsch MA-100). Apart from the BBDOAS data which were somewhat low and affected by a large scatter the agreement was satisfactory. At 10:20 we spiked the chamber air with $3.4 \mathrm{ppb}$ of HCHO. Taking into account that the $0.3-0.4 \mathrm{ppb}$ of $\mathrm{HCHO}$ already present in the ambient air matrix were not considered for $\mathrm{HCHO}_{\text {inj }}$ calculation, the calculated $\mathrm{HCHO}$ values are roughly a factor of 2 too high. This finding indicates that significant injection losses occurred during day 5. For level B, Hantzsch AL4021 and DNPH-HPLC data were in excellent agreement but the three other instruments reporting somewhat higher levels (PTR-MS: 0.2-0.4 ppb; Hantzsch MA-100: 0.8 ppb). 14 outliers in the 3 to $5 \mathrm{ppb}$ range were removed for the Hantzsch MA-100. Data from the DOAS instrument were in reasonable agreement at the beginning of level B. After $12: 00$, however, an upward drift of $\approx 0.5 \mathrm{ppb}$ was seen which remains unexplained.

In general, the experiment during day 5 was less well defined than the other synthetic air experiments. However, we included day 5 to show the good agreement before the HCHO injection at sub ppb levels. The differences between the instruments during the later period of the experiment are not understood and require more experiments with filtered ambient air inside SAPHIR.

\section{Conclusions}

A formal blind intercomparison exercise for the determination of atmospheric HCHO was conducted at the atmosphere simulation chamber SAPHIR at the Research Centre Jülich. Five state-of-the-art HCHO instruments (based on four different sensing principles) were deployed: a custombuilt DOAS instrument (optical spectroscopy), self-prepared 
DNPH cartridges for HPLC analysis (derivatizationchromatography), two different types of commercially available wet chemical sensors (Hantzsch fluorimetry) and a PTR-MS instrument (chemical ionization mass spectrometry). The deployed methods were independently calibrated. The instruments were challenged with typical ambient levels of HCHO ranging from tenths of a ppb to several ppb. During three experiments, synthetic air of high purity was used as sample matrices in the simulation chamber onto which $\mathrm{HCHO}$ was spiked under varying levels humidity and $\mathrm{O}_{3}$. Measurements were compared to mixing ratios calculated from the chamber volume and the known amount of $\mathrm{HCHO}$ injected into the chamber, summarized in Table 2. However, due to injection uncertainties, calculated HCHO mixing ratios were less accurate than previously reported (Brauers et al., 2007) and thus could not be used as a reference standard in this study. In a fourth experiment, using particulatefiltered ambient air, we observed a similar agreement between the methods but a larger difference to the calculated $\mathrm{HCHO}$ mixing ratio.

The intercomparison exercise revealed a series of analytical problems associated with the experimental set-up and individual instruments. In dry synthetic air, hydrazine-tohydrazone conversion was greatly suppressed in the DNPH cartridges resulting in highly under estimated HCHO levels by the DNPH-HPLC under this condition. The data of the Hantzsch MA-100 instrument equipped with a modified inlet system were affected by a non-constant offset under most conditions. It is unclear whether the observed discrepancies were caused by the modified inlet system or whether they arose from other instrumental deficiencies. With $\mathrm{O}_{3}$ present at $44 \pm 2 \mathrm{ppb}$ both DOAS and PTR-MS produced significantly higher levels than the Hantzsch AL4021 and the DNPH-HPLC. Based on the assumption that a positive ozone bias can be excluded with high confidence for the DOAS system we concluded that both the DNPH-HPLC and the Hantzsch AL4021 were affected by a negative ozone interference during part of the experiment. However, this interference was not observed in other experiments for the Hantzsch AL4021. The bias varied with time and/or HCHO concentration and remains unexplained.

Apart from the problems reported above the obtained agreement can be considered as fair. The PTR-MS in its optimized mode of operation proved to be a promising tool for online sub-ppb detection of $\mathrm{HCHO}^{2}$, also at low absolute humidities $(<1 \%)$. The detailed analysis, however, revealed a series of minor discrepancies, unresolved features and open questions remain to be answered before measurements of atmospheric $\mathrm{HCHO}$ with high accuracy and precision are guaranteed. A recommendation from this study is that a validated reference standard should be developed against which

\footnotetext{
${ }^{2}$ The use of PTR-MS for the detection of HCHO is also supported by Inomata et al. (2008), published during the review process of this paper.
}

the accuracy of the individual instruments can be assessed. The generation of defined atmospheres in SAPHIR seems a promising candidate since injection losses may be easily minimized using a heated transfer line. As for many previous $\mathrm{HCHO}$ intercomparisons the general conclusion of our efforts is that HCHO measurements at low-ppb levels are still problematic and that more validation work is needed.

Acknowledgements. This work was supported by the EU FP-6 programs ACCENT and EUROCHAMP. We acknowledge the inputs from all participants of the 2005 ACCENT OVOC intercomparison campaign. We thank R. Häseler and F. J. Johnen for the support with the experiments.

Edited by: L. Carpenter

\section{References}

Apel, E. C., Hills, A. J., Lueb, R., Zindel, S., Eisele, S., and Riemer, D. D.: A fast-GC/MS system to measure C-2 to C-4 carbonyls and methanol aboard aircraft, J. Geophys. Res., 108, 8794, doi:10.1029/2002JD003199, 2003.

Bossmeyer, J., Brauers, T., Richter, C., Rohrer, F., Wegener, R., and Wahner, A.: Simulation Chamber Studies on the $\mathrm{NO}_{3}$ Chemistry of Atmospheric Aldehydes, Geophys. Res. Lett., 33, L18810, doi:10.1029/2006GL026778, 2006.

Brauers, T., Bossmeyer, J., Dorn, H.-P.,Schlosser, E., Tillmann, R., Wegener, R., and Wahner, A.: Investigation of the formaldehyde differential absorption cross section at high and low spectral resolution in the simulation chamber SAPHIR, Atmos. Chem. Phys., 7, 3579-3586, 2007,

http://www.atmos-chem-phys.net/7/3579/2007/.

Dingle, P. and Franklin, P.: Formaldehyde levels and the factors affecting these levels in homes in Perth, western Australia, Indoor and Built Environment, 3(11), 111-116, 2002.

Fan, Q. and Dasgupta, P. K.: Continuous automated determination of atmospheric formaldehyde at the parts per trillion levels, Anal. Chem., 66, 551-556, 1994.

Finlayson-Pitts, B. J. and Pitts, J. N.: Chemistry of the Upper and Lower Atmosphere - Theory, Experiments and Applications, Academic Press, San Diego, 2000.

Gratien, A., Picquet-Varrault, B., Orphal, J., Perraudin, E., Doussin, J.-F., and Flaud, J.-M.: Laboratory intercomparison of the formaldehyde absorption cross sections in the infrared (1660$\left.1820 \mathrm{~cm}^{-1}\right)$ and ultraviolet $(300-360 \mathrm{~nm})$ spectral regions, J. Geophys. Res., 112, D05305, doi:10.1029/2006JD007201, 2007.

Hak, C., Pundt, I., Trick, S., Kern, C., Platt, U., Dommen, J., Ordóñez, C., Prévôt, A. S. H., Junkermann, W., Astorga-Lloréns, C., Larsen, B. R., Mellqvist, J., Strandberg, A., Yu, Y., Galle, B., Kleffmann, J., Lörzer, J. C., Braathen, G. O., and Volkamer, R.: Intercomparison of four different in-situ techniques for ambient formaldehyde measurements in urban air, Atmos. Chem. Phys., 5, 2881-2900, 2005, http://www.atmos-chem-phys.net/5/2881/2005/.

Heard, D. E. (Ed.): Analytical Techniques for Atmospheric Measurement, Blackwell Publishing, ISBN 1405123575, Oxford, UK, 2006.

Inomata, S., Tanimoto, H., Kameyama, S., Tsunogai, U., Irie, H., Kanaya, Y., and Wang, Z.: Technical Note: Determination of 
formaldehyde mixing ratios in air with PTR-MS: laboratory experiments and field measurements, Atmos. Chem. Phys., 8, 273284, 2008,

http://www.atmos-chem-phys.net/8/273/2008/.

Junkermann, W. and Burger, J. M.: A new portable instrument for continuous measurement of formaldehyde in ambient air, J. Atmos. Ocean. Tech., 23(1), 38-45, 2006.

Karl, T., Jobson, T., Kuster, W.C., Williams, E., Stutz, J., Shetter, R., Hall, S. R., Goldan, P., Fehsenfeld, F., and Lindinger, W.: Use of proton-transfer-reaction mass spectrometry to characterize volatile organic compound sources at the La Porte super site during the Texas Air Quality Study 2000, J. Geophys. Res., 108, 4508, doi:10.1029/2002JD003333, 2003.

Kleffmann, J., Lörzer, J. C., Wiesen, P., Kern, C., Trick, S., Volkamer, R., Rodenas, M., and Wirtz, K.: Intercomparison of the DOAS and LOPAP techniques for the detection of nitrous acid (HONO), Atmos. Environ., 40, 3640-3652, 2006.

Koppmann, R. and Wildt, J.: Oxygenated Volatile Organic Compounds, in: Volatile Organic Compounds in the Atmosphere, edited by: Koppmann, R., Blackwell Publishing Ltd., Oxford, 129-172, 2007

Kraus, S. and Geyer, A.: DOASIS Jscript programming description, Institut für Umweltphysik, University of Heidelberg, 2001.

Li, J., Dasgupta, P. K., Genfa, Z., and Hutterli, M. A.: Measurement of Atmospheric Formaldehyde with a Diffusion scrubber and light-emitting diode-liquid-core wave-guide based fluorometry, Field Anal. Chem. Tech., 5(1-2), 2-12, 2001.

Lindinger, W., Hansel, A., and Jordan, A.; Proton-transfer-reaction mass spectrometry (PTR-MS): on-line monitoring of volatile organic compounds at pptv levels, Chem. Soc. Rev., 27, 347-354, 1998.

Liu, L., Flatøy, F., Ordóñez, C., Braathen, G. O., Hak, C., Junkermann, W., Andreani-Aksoyoglu, S., Mellqvist, J., Galle, B., Prévôt, A. S. H., and Isaksen, I. S. A.: Photochemical modelling in the Po basin with focus on formaldehyde and ozone, Atmos. Chem. Phys., 7, 121-137, 2007, http://www.atmos-chem-phys.net/7/121/2007/.

Meller, R. and Moortgat, G. K.: Temperature dependence of the absorption cross sections of formaldehyde between 223 and $323 \mathrm{~K}$ in the wavelength range $225-375 \mathrm{~nm}$, J. Geophys. Res., 201(D6), 7089-7101, 2000.

Müller, K.: Determination of aldehydes and ketones in the atmospherea comparative long time study at an urban and a rural site in Eastern Germany, Chemosphere, 35, 2093-2106, 1997.

Platt, U.: Differential Optical Absorption Spectroscopy, Air Monitoring by, in: Encyclopedia of Analytical Chemistry, edited by: Meyers, R. A., John Wiley \& Sons Ltd (Chichester), 1936, 2000.

Rohrer, F., Bohn, B., Brauers, T., Brüning, D., Johnen, F.-J., Wahner, A., and Kleffmann, J.: Characterisation of the photolytic HONO-source in the atmosphere simulation chamber SAPHIR, Atmos. Chem. Phys., 5, 2189-2201, 2005, http://www.atmos-chem-phys.net/5/2189/2005/.

Rumchev, K. B., Spickett, J. T., Bulsara, M. K., Phillips, M. R., and Stick, S. M.: Domestic exposure to formaldehyde significantly increases the risk of asthma in young children, Eur. Respir. J., 20, 403-406, 2002.
Schlosser, E., Bohn, B., Brauers, T., Dorn, H.-P., Fuchs, H., Häseler, R., Hofzumahaus, A., Holland, F., Rohrer, F., Rupp, L. O., Siese, M., Tillmann, R., and Wahner, A.: Intercomparison of Two Hydroxyl Radical Measurement Techniques at the Atmosphere Simulation Chamber SAPHIR, J. Atmos. Chem., 56, 187-205, doi:10.1007/s10874-006-9049-3, 2006.

Slemr, J.: Determination of volatile carbonyl compounds in clean air, Fresenius J. Anal. Chem., 340, 672-677, 1991.

Solomon, S. J., Custer, T., Schade, G. W., Soares Dias, A. P., and Burrows, J. P.: Atmospheric methanol measurement using selective catalytic methanol to formaldehyde conversion, Atmos. Chem. Phys., 5, 2787-2796, 2005,

http://www.atmos-chem-phys.net/5/2787/2005/.

Solomon, S. J., Schade, G. W., Ladstätter-Weissenmayer, A., Kuttippurath., J., and Burrows, J. P: VOC concentrations in an indoor workplace environment of a university building, Indoor and Built Environ., in press, 2008.

Sprung, D., Jost, C., Reiner, T., Hansel, A., and Wisthaler, A: Airborne measurements of acetone and acetonitrile in the tropical Indian Ocean boundary layer and free troposphere: Aircraft-based intercomparison of AP-CIMS and PTR-MS measurements, J. Geophys. Res., 106(22), 28 511-28 528, 2001.

Steinbacher, M., Dommen, J., Ammann, C., Spirig, C., Neftel, A., and Prevot, A. S. H.: Performance characteristics of a protontransfer-reaction mass spectrometer (PTR-MS) derived from laboratory and field measurements, Int. J. Mass Spectrom., 239, 117-128, 2004.

Sumner, A. L., Shepson, P. B., Grannas, A. M., Bottenheim, J. W., Anlauf, K. G., Worthy, D., Schroeder, W. H., Steffen, A., Domine, F., Perrier, S., and Houdier, S.: Atmospheric chemistry of formaldehyde in the Arctic troposphere at Polar Sunrise, and the influence of the snowpack, Atmos. Environ., 36, 15-16, 2002.

Tago, H. , Kimura, H., Kozawa, K., and Fujie, K.: Formaldehyde concentrations in ambient air in urban and rural areas in Gunma prefecture, Japan, Water Air Soil Pollut., 163, 269-280, 2002.

Wegener, R., Brauers, T., Koppmann, R.Rodríguez Bares, S., Rohrer, F., Tillmann, R., Wahner, A., Hansel, A., and Wisthaler, A.: Investigation of the ozonolysis of short chained alkenes in the atmosphere simulation chamber SAPHIR, J. Geophys. Res., 112, D13301, doi:10.1029/2006JD007531, 2007.

Wisthaler, A., Hansel, A., Koppmann, R., Brauers, T., Bossmeyer, J., Steinbrecher, R., Junkermann, W., Müller, K. , Solomon, S. J., and Apel, E. C.: PTR-MS measurements of HCHO and results from $\mathrm{HCHO}$ intercomparison measurements in the atmosphere simulation chamber SAPHIR, Geophys. Res. Abstr., 8, 04776, 2006.

Zhang, J., He, Q., and Lioy, P. J.: Characteristics of aldehydes: concentrations, sources, and exposures for indoor and outdoor residential microenvironments, Environ. Sci. Technol., 28, 146152, 1994. 